\title{
The Metabolism of $\left[\mathrm{Me}^{-14} \mathrm{C}\right] \mathrm{Choline}$ in the Brain of the Rat in vivo
}

\author{
By G. B. ANSELL AND SHEILA SPANNER \\ Department of Experimental Neuropharmacology, The Medical School, \\ University of Birmingham
}

(Received 19 July 1968)

\begin{abstract}
$\left[\mathrm{Me}-{ }^{14} \mathrm{C}\right] \mathrm{Choline}$ was injected intracerebrally into the adult rat, and its uptake into the lipids and their water-soluble precursors in brain was studied. The radioactivity could be detected only in the choline-containing lipids and was confined to the base choline. The results indicated that initial phosphorylation of the free choline followed by the formation of CDP-choline and the subsequent transfer of the phosphorylcholine to a diglyceride is one of the principal routes by which choline lipids in brain are formed. Further evidence for this was obtained in experiments in which either phosphoryl $\left[\mathrm{Me}^{14} \mathrm{C}\right]$ choline or $\left[{ }^{32} \mathrm{P}\right]$ orthophosphate was injected and the radioactivity in the choline-containing water-soluble and lipidbound components studied.
\end{abstract}

Several workers have studied the metabolism of lipid components after the intracerebral injection of lipid precursors. Bickerstaffe \& Mead (1967) injected $\left[1-{ }^{14} \mathrm{C}\right]$ palmitaldehyde into rat brains and traced its metabolism in the phospholipids. Kopaczyk \& Radin (1965) used [1-14C]lignoceric acid and $\left[1{ }^{14} \mathrm{C}\right]$ stearic acid in a study of brain sphingolipid metabolism. Davison \& Gregson (1966) gave rats intracerebral injections of inorganic [35S]sulphate to study the metabolic activity of sulphatides in myelin. Other workers injected [32P]orthophosphate (Ansell \& Chojnacki, 1964), ${ }^{3} \mathrm{H}$-labelled erythro- and threo-sphingosine (Kanfer \& Gal, 1966) and $\left.{ }^{14} \mathrm{C}\right]$ serine (Abdel-Latif \& Abood, 1966), and studied their incorporation into the brain lipids.

As far as we are aware no one has reported on the fate of intracerebrally injected labelled choline, although the metabolism of choline lipids, in particular phosphatidylcholine, has been studied extensively in tissues. Groth, Bain \& Pfeiffer (1958) studied the fate of both ${ }^{14} \mathrm{C}$-labelled choline and ${ }^{14} \mathrm{C}$-labelled 2-dimethylaminoethanol after intraperitoneal injection, but they examined only the incorporation into the total acid-soluble and lipidbound choline of the brain. The metabolism of choline in the brain is of interest because choline does not appear to be synthesized in this tissue (Marshall, Chojnacki \& Ansell, 1965; Ansell \& Spanner, 1967).

In the present work $\left[\mathrm{Me}^{-14} \mathrm{C}\right]$ choline was injected intracerebrally into mature rats and its subsequent metabolism was studied. Preliminary reports of this work have been published (Ansell \& Spanner, 1966, 1968).

\section{MATERIALS AND METHODS}

Materials. $\left[\mathrm{Me}-{ }^{14} \mathrm{C}\right] \mathrm{Choline}$ and $\left[{ }^{32} \mathrm{P}\right]$ orthophosphate were obtained from The Radiochemical Centre, Amersham, Bucks. Phosphoryl $\left[\mathrm{Me}^{-14} \mathrm{C}\right]$ choline was prepared as described for the 32P-labelled compound by Ansell \& Chojnacki (1966). The purity of the radioactive chemicals was checked by paper chromatography followed by radioautography just before use. All chemicals were of A.R. quality whenever possible. The rats used were females, 230-250g. body wt., and 12-14 weeks old.

Injections. The rats were anaesthetized and the radioactive compounds injected as described by Ansell \& Spanner (1967). In the experiments described below, two different amounts of $\left[\mathrm{Me}^{-14} \mathrm{C}\right] \mathrm{choline}, 0.55 \mu \mathrm{C}(0.017 \mu \mathrm{mole})$ and $1.0 \mu \mathrm{c}(0.03 \mu \mathrm{mole})$, were injected. With [ $\left.{ }^{32} \mathrm{P}\right]$ orthophosphate, $10 \mu \mathrm{c}(0.32 \mu \mathrm{mole})$ was injected, and with phosphoryl $\left[M e-{ }^{14} \mathrm{C}\right]$ choline, $0.035 \mu \mathrm{C} \quad(0.029 \mu$ mole $)$ was injected.

Extraction and determination of water-soluble components. The brains were removed, weighed and homogenized with ice-cold trichloroacetic acid $(10 \%, w / v)$, and the watersoluble components were separated on Dowex 1 (X8; formate form). The elution pattern for the cholinecontaining compounds was almost the same as that for the analogous ethanolamine compounds described by Ansell \& Spanner (1967). The choline was eluted with the water; phosphorylcholine and CDP-choline were then eluted with increasing concentrations of formic acid. The water eluate from the column was evaporated to dryness and the residue dissolved in $1 \mathrm{ml}$. of $5 \%(\mathrm{w} / \mathrm{v})$ trichloroacetic acid, and the free choline was determined by the method of Long, Odavić \& Sargent (1967). This fraction included choline originally present as acetylcholine since this would have been hydrolysed when the $\mathrm{pH}$ of the original extract was adjusted to 8.5 before column chromatography. Since the acetylcholine concentration in rat brain $(0.007 \mu$ mole $/ \mathrm{g}$. fresh wt.; Richter \& Crossland, 1949) is only $4 \%$ of the free 
choline pool, it was ignored when calculations of the specific radioactivity of free choline were made. The choline- and ethanolamine-containing components of the radioactive peaks, other than free choline, were separated by paper chromatography (Ansell \& Spanner, 1967).

Extraction and determination of phospholipids. The brains were removed and weighed, and the lipids were extracted and washed by the method of Folch, Lees \& Sloane-Stanley (1957). The choline-containing phospholipids were isolated by chromatography on a column of alumina (Davison \& Wajda, 1959). These choline lipids were separated into an alkali-labile fraction (phosphatidylcholine), an alkali-stable acid-labile fraction (choline plasmalogen) and an alkali- and acid-stable fraction (sphingomyelin) by the hydrolytic procedures of Dawson, Hemington \& Davenport (1962). In this instance the more prolonged saponification necessary to remove the fatty acid from the 2-position of the ethanolamine plasmalogen (Ansell \& Spanner, 1963) was found unnecessary. For experiments in which the determination of choline plasmalogen was not required, the trichloroacetic acid-insoluble residue (see above) was washed twice with water and the lipids were extracted and washed by the method of Folch et al. (1957).

The fractions were assayed for radioactivity and phosphorus. Phosphorus determinations were carried out by the method of Ernster, Zetterström \& Lindberg (1950), modified where necessary to increase the sensitivity by using half volumes of the reagents.

Assay of radioactivity. The ${ }^{14} \mathrm{C}$-labelled samples were counted in a Packard liquid-scintillation counter and the 32-p-labelled samples in a M6 liquid-counting tube (20th Century Electronics) with standard ancillary equipment. The scintillator used was described by Ansell \& Spanner (1967). The counts of the ${ }^{14} \mathrm{C}$-labelled samples were corrected to $100 \%$ efficiency by the channels-ratio method.

\section{RESULTS}

Uptake of $\left[\mathrm{Me}-{ }^{14} \mathrm{C}\right]$ choline by whole brain and the distribution in the acid-soluble components. When $\left[\mathrm{Me}-{ }^{14} \mathrm{C}\right]$ choline was injected into the brain of rats in the region of the lateral ventricle, there was a rapid dispersal of the choline. The same amount of radioactivity was found in each hemisphere when measured $30 \mathrm{~min}$. after the injection. There was, however, a rapid loss of total radioactivity from the brain. After only $30 \mathrm{~min} ., 60 \%$ of the radioactivity injected as choline had disappeared (Fig. 1). In this, labelled choline differed from $\left[1,2-1^{4} \mathrm{C}_{2}\right]-$ ethanolamine (Ansell \& Spanner, 1967), 70\% of whose radioactivity could be recovered from the brain as long as $10 \mathrm{hr}$. after the injection.

There was a rapid transfer of labelled choline from the acid-soluble pool to the lipids (Fig. 1) so that, within $6 \mathrm{hr}$., $85 \%$ of the radioactivity in the brain was in a lipid-bound form. The concentrations of the water-soluble components, choline, phosphorylcholine and CDP-choline, in brain were measured (Table 1) and their respective radioactivities after a number of exchange periods were determined. Fig. 2 shows there that was a rapid

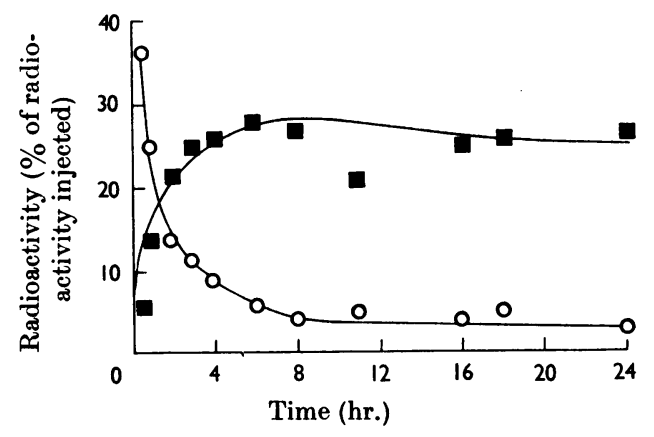

Fig. 1. Percentages of radioactivity injected as [Me-14 $\mathrm{C}]-$ choline recovered in the brain at various times after injection. O, Acid-soluble fraction; $\square$, lipid fraction. Each point represents the mean obtained from two or three animals.

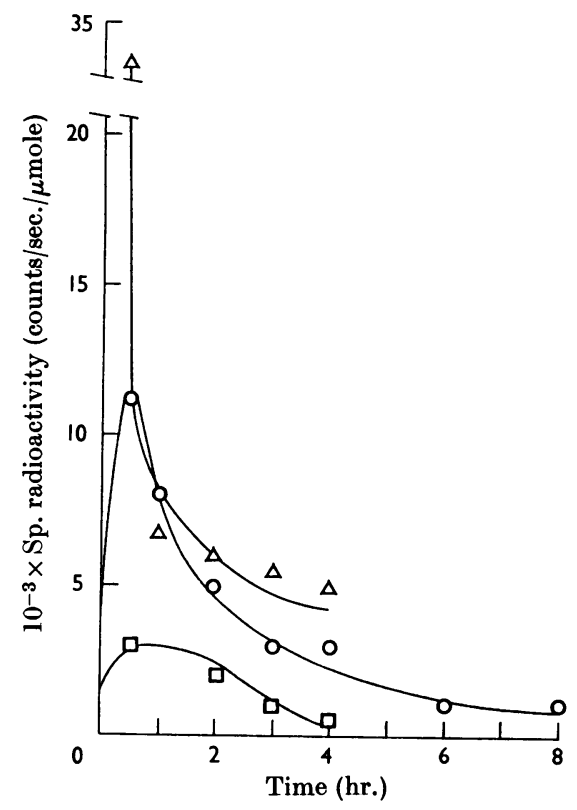

Fig. 2. Specific radioactivities of acid-soluble choline components in the brain at various times after the injection of $\left[M e-{ }^{14} \mathrm{C}\right]$ choline. $\triangle$, Choline; $\bigcirc$, phosphorylcholine; $\square$, CDP-choline.

phosphorylation of free choline at a minimum rate of $0.076 \mu \mathrm{mole} / \mathrm{g}$. of brain $/ \mathrm{hr}$. The specific radioactivity-time curve for choline crosses that of phosphorylcholine at a point where the specific radioactivity of phosphorylcholine was maximal, which suggests a direct precursor-product relationship (Zilversmit, Entenman \& Fishler, 1943). The CDP-choline was also labelled, but incorporation 
Table 1. Concentration of choline lipids and their water-soluble precursors in rat brain

Values are given as means \pm S.D., with the numbers of determinations in parentheses.

Concn. ( $\mu$ moles/g. of brain fresh wt.)

\begin{abstract}
Choline
Phosphorylcholine

CDP-choline

Phosphatidylcholine

Choline plasmalogen

Sphingomyelin
\end{abstract}

\begin{tabular}{|c|c|}
\hline Present work & Values in the literature \\
\hline $0.17 \pm 0.01(5)$ & $0 \cdot 20^{*}$ \\
\hline $0.38 \pm 0.05(10)$ & $0.442 \dagger ; 0.390 \ddagger$ \\
\hline $0.05 \pm 0.006(7)$ & $0.03 \S$ (4-week-old animals) \\
\hline $14 \cdot 70 \pm 1 \cdot 50(39)$ & - \\
\hline $0.62 \pm 0.08(9)$ & $0.47 \pi ; 0.22-0.35 \|$ \\
\hline $3 \cdot 65 \pm 0 \cdot 24(6)$ & $3 \cdot 63-3 \cdot 70 \|$ \\
\hline
\end{tabular}

\footnotetext{
* Dr C. Hebb, personal communication (determined by conversion into acetylcholine followed by bioassay).

$\dagger$ Dawson (1955).

$\ddagger$ Porcellati (1958).

$\S$ Ansell \& Bayliss (1961).

|| Wells \& Dittmer (1967).

If Webster (1960).
}

into it was curiously low compared with the labelling of CDP-ethanolamine after the injection of $\left[1,2 \cdot{ }^{14} \mathrm{C}_{2}\right]$ ethanolamine (Ansell \& Spanner, 1967).

Incorporation of $\left[\mathrm{Me}-{ }^{14} \mathrm{C}\right]$ choline into the phospholipids of brain. It was shown in Fig. 1 that the lipids of the brain were rapidly labelled after the injection of $\left[\mathrm{Me}^{\left.1{ }^{14} \mathrm{C}\right] \text { choline. The choline-contain- }}\right.$ ing fraction eluted from the alumina column contained $100 \%$ of the counts recovered in the total lipid. This choline-containing lipid was then hydrolysed in $6 \mathrm{~N}$-hydrochloric acid for $3 \mathrm{hr}$. at $100^{\circ}$ under reflux. Fractionation of the watersoluble products on Dowex 1 (X8; $\mathrm{OH}^{-}$form) showed that all the radioactivity in the choline lipids was in the base. Thus in a typical experiment, with a $3 \mathrm{hr}$. exchange period, the radioactivity (counts/sec./brain) was : $\mathbf{8 1 8 0}$ for total lipid, $\mathbf{8 0 0 0}$ for the choline lipid and $\mathbf{7 8 2 5}$ in the lipid-bound choline. When a sample of the total lipid extract was separated by thin-layer chromatography on silica gel $\mathrm{G}$ in chloroform-methanol-water $(65: 35: 4$, by vol.) and the radioactive lipids were located by radioautography, only phosphatidylcholine + choline plasmalogen, lysophosphatidylcholine and sphingomyelin were labelled.

Of the three major choline-containing lipids in brain (Table 1), by far the greatest radioactivity at all the times examined was in the phosphatidylcholine (Fig. 3). There was considerable labelling of the choline plasmalogen, but the sphingomyelin showed only a small uptake of the labelled choline (Fig. 3).

Uptake of phosphoryl[ $\left.\mathrm{Me}-{ }^{14} \mathrm{C}\right]$ choline into brain water-soluble and lipid fractions. When phosphoryl$\left[\mathrm{Me}{ }^{14} \mathrm{C}\right]$ choline was injected into the brain there was, as with choline, a rapid loss of the label from the brain. There was a very similar pattern of

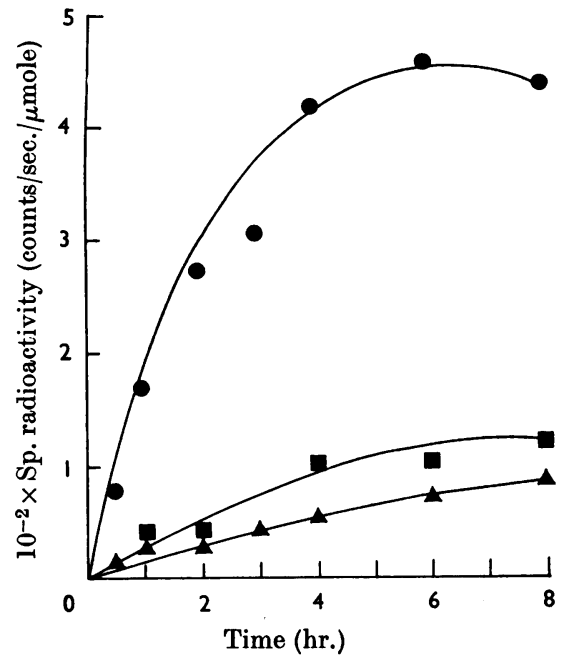

Fig. 3. Specific radioactivities of the choline-containing phospholipids in the brain at various times after the injection of $\left[\mathrm{Me}^{-14} \mathrm{C}\right]$ choline. $\bullet$, Phosphatidylcholine; $\boldsymbol{\square}$, choline plasmalogen; $\Delta$, sphingomyelin.

transfer of water-soluble radioactivity to lipid components, though at a somewhat lower rate (Fig. 4). This may have been due, partly, to the initial breakdown of the phosphorylcholine on injection that is shown in Fig. 5. After this initial hydrolysis of injected phosphorylcholine, there was a rapid equilibration between the specific radioactivity of the choline and the phosphorylcholine (Fig. 5), as was shown after the injection of $\left[M e^{-14} \mathrm{C}\right]$ choline (Fig. 2).

Comparison of the specific radioactivities of phosphorylcholine and of phosphatidylcholine after the 


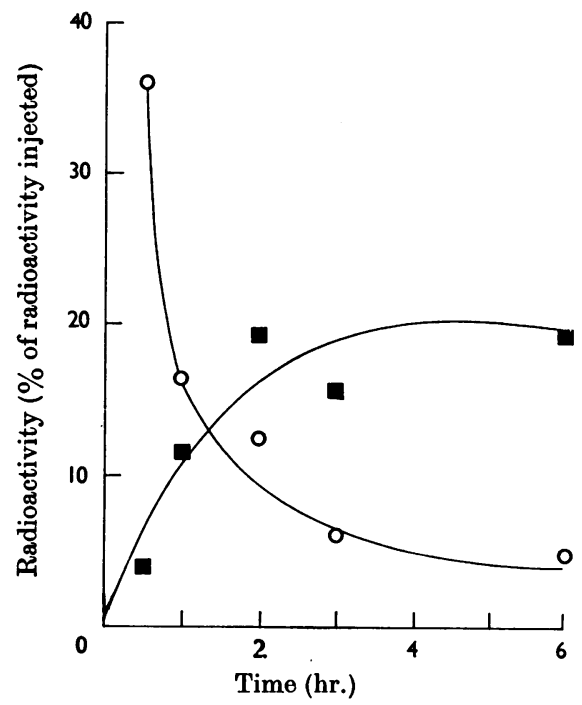

Fig. 4. Percentages of radioactivity injected as phosphoryl[ $\left.M e-{ }^{14} \mathrm{C}\right]$ choline recovered in the brain. $O$, Acidsoluble choline; $\square$, lipid-bound choline.

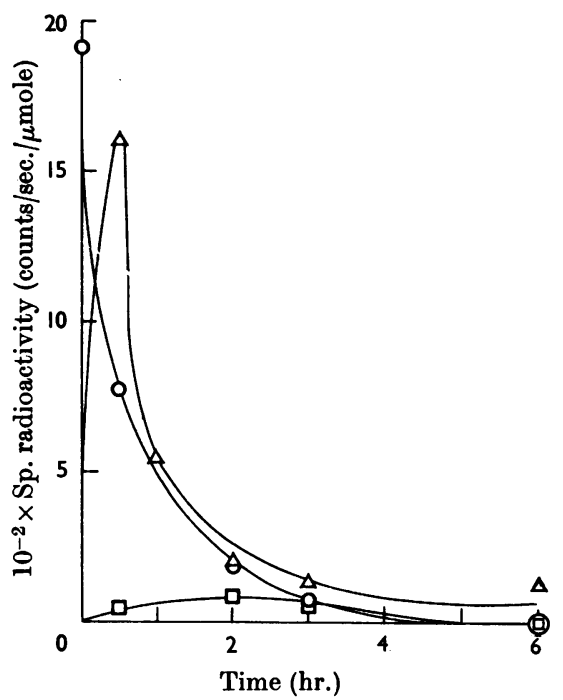

Fig. 5. Specific radioactivities of acid-soluble choline components in the brain at various times after the injection of phosphoryl[ $\left.\mathrm{Me}^{14} \mathrm{C}\right]$ choline. $\triangle$, Choline; $O$, phosphorylcholine; $\square$, CDP-choline.

injection of labelled choline, phosphorylcholine and orthophosphate. It was found that when [32P]orthophosphate was injected into the brain of the rat the rate of transfer of phosphorylcholine to

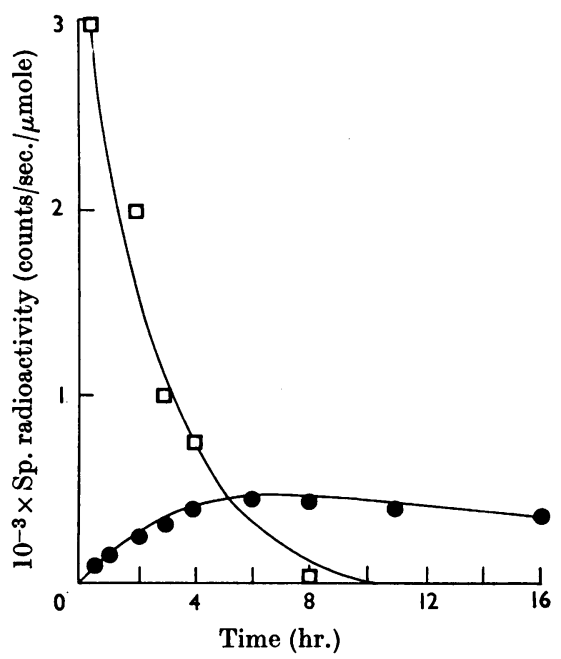

Fig. 6. Specific radioactivities of the brain CDP-choline $(\square)$ and phosphatidylcholine $(\bullet)$ at various times after the injection of $\left[M e^{-14} \mathrm{C}\right]$ choline.

phosphatidylcholine, as measured by the ratio of the two specific radioactivities, was very similar to that found after the injection of $\left[\mathrm{Me}^{-14} \mathrm{C}\right] \mathrm{choline}$ (Table 2). Further, it was found that, for the few experiments where phosphoryl[ $\mathrm{Me}^{\left.-{ }^{14} \mathrm{C}\right] \text { choline was }}$ injected, the ratio of the specific radioactivity of phosphatidylcholine to that of phosphorylcholine was also similar to that obtained with [ $\left.{ }^{32} \mathrm{P}\right]$ ortho-

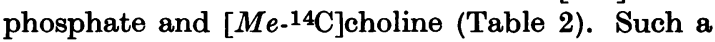
close correlation would suggest an obligatory phosphorylation of the choline before its incorporation into phosphatidylcholine.

\section{DISCUSSION}

When $\left[M e-{ }^{14} \mathrm{C}\right]$ choline or phosphoryl $\left[M e^{-14} \mathrm{C}\right]$. choline was injected into brain by the intracerebral route, there was initially a very rapid loss of the radioactivity. At $0.5 \mathrm{hr}$. after injection, only $40 \%$ of the injected dose was recovered in the brain (Figs. 1 and 4). This amount was, however, maintained and after $24 \mathrm{hr}$. over $30 \%$ of the injected label was still recovered (Fig. 1). This result was very different from that obtained with $\left[{ }^{14} \mathrm{C}\right]$ ethanolamine (Ansell \& Spanner, 1967), when after an exchange period of $1 \mathrm{hr} .88 \%$ of the injected dose was recovered but after $24 \mathrm{hr}$. this value had dropped to $47 \%$ of that injected. This rapid initial loss of choline and phosphorylcholine is difficult to explain. Overloading the brain pool was not apparently the reason for the rapid loss. If the amount of choline injected was $0.017 \mu$ mole instead of $0.03 \mu \mathrm{mole}$ $(5.6 \%$ of the brain pool instead of $10 \%)$, the 


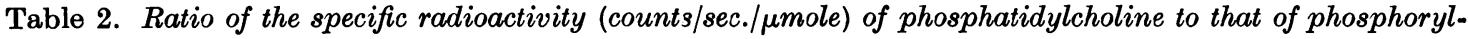
choline of brain after the injection of $\left[M e-{ }^{14} \mathrm{C}\right]$ choline, phosphoryl[Me-14 $\left.\mathrm{C}\right]$ choline or $\left[{ }^{32} \mathrm{P}\right]$ orthophosphate

Numbers of determinations made are given in parentheses.

\begin{tabular}{|c|c|c|c|c|}
\hline \multirow{2}{*}{$\begin{array}{c}\text { Time after } \\
\text { injection } \\
\text { (hr.) }\end{array}$} & \multirow[b]{2}{*}{ Substance injected } & \multicolumn{3}{|c|}{ Phosphatidylcholine/phosphorylcholine sp. radioactivity ratio } \\
\hline & & $\ldots\left[\mathrm{Me}-{ }^{14} \mathrm{C}\right]$ Choline & Phosphoryl $\left[M e^{-14} \mathrm{C}\right]$ choline & [32P]Orthophosphate \\
\hline 1 & & $0 \cdot 013(3)$ & 0.011 & 0.010 \\
\hline 2 & & $0 \cdot 034$ & 0.040 & 0.032 \\
\hline 3 & & $0.080(2)$ & 0.075 & $0 \cdot 071$ \\
\hline 4 & & $0 \cdot 170(2)$ & - & $0 \cdot 097$ \\
\hline 6 & & $0 \cdot 239$ & - & $0 \cdot 185$ \\
\hline 8 & & 0.307 & - & $0 \cdot 203$ \\
\hline
\end{tabular}

percentage of radioactivity recovered was identical. Results from experiments with both amounts are included in Fig. 1.

The rapid appearance of labelled phosphorylcholine after the injection of labelled choline indicated a rapid phosphorylation of this base, presumably by the enzyme choline kinase (EC 2.7.1.32). The rate of this phosphorylation $(0.076 \mu \mathrm{mole} / \mathrm{g}$. of brain/hr.) was low compared with the rate ( $2 \mu$ moles/g. of grey matter/hr.) found in vitro at neutral $\mathrm{pH}$ by McCaman (1962). The rate found in vivo for the phosphorylation of choline was about $50 \%$ of that found for the phosphorylation of ethanolamine (Ansell \& Spanner, 1967). On the other hand, the concentration of free choline in the brain ( $0 \cdot 17 \mu$ mole/g. of brain) was only about onetenth of that of ethanolamine $(1.35 \mu$ moles $/ g$. of brain).

From the relationship between the specific radioactivity-time curves in Fig. 2, it appears that choline is the precursor of phosphorylcholine and phosphorylcholine the precursor of CDP-choline. However, if the criteria of Zilversmit et al. (1943) are applied, the curve for the precursor would have to be initially higher than that of the product, cross the latter at its peak and then fall below it. These criteria are not entirely fulfilled for choline-phosphorylcholine or phosphorylcholineCDP-choline. It is, of course, unusual for the ideal criteria of Zilversmit et al. (1943) to be fulfilled in a biological system (Reiner, 1953), though they appear to be for the relationship between CDP. choline and phosphatidylcholine in Fig. 6. It is possible that there are intermediate steps, for example an active transport of phosphorylcholine to the site of CDP-choline synthesis, that might account for the discrepancies in Fig. 2. Nevertheless the results indicate strongly that the major pathway for the incorporation of choline into phosphatidylcholine in brain is the cytidine pathway. Further evidence is given in Table 2. This pathway has been demonstrated for brain tissue in vitro on a number of occasions (see, e.g., Rossiter, 1964).

A comparison between Fig. 2 and Fig. 5 indicates further the closeness of the relationship between choline and phosphorylcholine in brain. Just as there was a rapid formation of labelled phosphorylcholine from labelled choline, the reverse was also true. Within $2 \mathrm{hr}$. an equilibrium was established between the two compounds with the specific radioactivity of the choline slightly higher than that of the phosphorylcholine in both instances.

The specific radioactivity-time curves for CDP. choline and phosphatidylcholine in brain (Fig. 6) indicate a relationship between these two compounds that is different from that found in liver by Bjørnstad \& Bremer (1966). They showed that, when $\left[1,2-14 \mathrm{C}_{2}\right]$ choline was injected intraperitoneally, the phosphorylcholine, CDP-choline and phosphatidylcholine of liver were all labelled but that the specific radioactivity of the CDP. choline was very low compared with that of the phosphorylcholine up to $80 \mathrm{~min}$. It was more comparable with that of phosphatidylcholine, suggesting that in this instance the specific radioactivity of the CDP-choline was kept low by equilibrium with preformed phosphatidylcholine. This was confirmed by experiments with [Me- $\left.{ }^{3} \mathrm{H}\right]$ methionine, which, when injected intraperitoneally, yielded labelled phosphatidylcholine of much greater specific radioactivity than phosphorylcholine but of similar specific radioactivity to CDP-choline. In the results presented in Fig. 6 no such equilibration of CDP-choline with phosphatidylcholine in brain could be demonstrated.

The results suggest that the cytidine pathway is very important in the synthesis of phosphatidylcholine in the brain, and the question of the source of the choline therefore arises. Ansell \& Spanner (1967) observed very little conversion of radioactive ethanolamine into choline in the brain of the rat, in the free state, or as phosphorylethanolamine or as lipid-bound ethanolamine. Bremer \& Greenberg 
(1961) could not demonstrate significant methylation of the endogenous ethanolamine phospholipids present in brain microsomes by L-S-adenosyl[Me- $\left.{ }^{14} \mathrm{C}\right]$ methionine. Marshall et al. (1965) also failed to demonstrate the methylation of [ $\left.{ }^{32} \mathrm{P}\right]$ phosphatidyldimethylaminoethanol or [ $\left.{ }^{32} \mathrm{P}\right]$ phosphatidylmonomethylaminoethanol by $S$-adenosyl$\left[\mathrm{Me}{ }^{14} \mathrm{C}\right]$ methionine in brain dispersions. On injection of $\left[M e^{-3} \mathrm{H}\right]$ methionine into rats, the labelling of the phosphatidylcholine in extrahepatic tissues was slow compared with the labelling in the liver (Bjørnstad \& Bremer, 1966); similar observations were made on lung tissue by Spitzer, Morrison \& Norman (1968). The labelling in brain was not investigated.

Such observations suggest that choline is supplied to the brain from the liver. There is no doubt that injected labelled choline is incorporated into lipids of all organs. Groth et al. (1958) showed that $\left[M e-{ }^{14} \mathrm{C}\right]$ choline and $\left[1,2-{ }^{14} \mathrm{C}_{2}\right]$ choline were taken up into brain phosphatidylcholine, though the methyl-labelled choline was a more effective precursor than the hydroxyethyl-labelled choline. Bjørnstad \& Bremer (1966) showed, moreover, that the uptake of labelled choline into extrahepatic tissues was decreased when the amount of free circulating unlabelled choline was artificially raised. However, the labelling of the lipids in extrahepatic tissues after the injection of $\left[\mathrm{Me}^{-3} \mathrm{H}\right]$ methionine was not decreased by choline injection. From these experiments Bjørnstad \& Bremer (1966) concluded that, if choline was being made in the liver by the methylation pathway and transported to other tissues for utilization via the cytidine pathway, it was not transported as free choline.

The route by which choline enters the choline plasmalogen of brain is less clear. At least two routes are possible and there may well be more. The cytidine pathway with a plasmalogenic diglyceride (2-acyl-1-alk-1'-enylglycerol) as substrate was demonstrated in vitro by McMurray \& Rossiter (1962) and by E. F. Marshall (unpublished work). One difficulty in accepting this route is that no plasmalogenic diglyceride has, as yet, been detected in brain. The formation of the plasmalogen from the diacyl phospholipid was also postulated for the ethanolamine analogue by Bickerstaffe \& Mead (1967). The results described in this paper and shown in Fig. 3 would indicate that the choline plasmalogen could be formed from the diacyl phospholipid, but experiments of a different type would be necessary to prove it.
The authors thank Professor P. B. Bradley for his interest in this work.

\section{REFERENCES}

Abdel-Latif, A. A. \& Abood, L. G. (1966). J. Neurochem. $13,1189$.

Ansell, G. B. \& Bayliss, B. J. (1961). Biochem. J. 78, 209. Ansell, G. B. \& Chojnacki, T. (1964). In Biochemical Problems of Lipids, p. 425. Ed. by Frazer, A. C. Amsterdam: Elsevier Publishing Co.

Ansell, G. B. \& Chojnacki, T. (1966). Biochem. J. 98, 303. Ansell, G. B. \& Spanner, S. (1963). J. Neurochem. 10, 941. Ansell, G. B. \& Spanner, S. (1966). Biochem. J. 100, 50 P.

Ansell, G. B. \& Spanner, S. (1967). J. Neurochem. 14, 873. Ansell, G. B. \& Spanner, S. (1968). Biochem. J. 106, 20 P.

Bickerstaffe, R. \& Mead, J. F. (1967). Biochemistry, 6, 655. Bjørnstad, P. \& Bremer, J. (1966). J. Lipid Res. 7, 38.

Bremer, J. \& Greenberg, D. M. (1961). Biochim. biophys. Acta, 46, 205.

Davison, A. N. \& Gregson, N. A. (1966). Biochem. J. 98, 915.

Davison, A. N. \& Wajda, M. (1959). J. Neurochem. 4, 353.

Dawson, R. M. C. (1955). Biochem. J. 60, 325.

Dawson, R. M. C., Hemington, N. \& Davenport, J. B. (1962). Biochem. J. 84, 497.

Ernster, L., Zetterström, R. \& Lindberg, O. (1950). Acta chem. scand. 4, 942.

Folch, J., Lees, M. \& Sloane-Stanley, G. H. (1957). J. biol. Chem. 226, 497.

Groth, D. P., Bain, J. A. \& Pfeiffer, C. C. (1958). J. Pharmacol. 124, 290.

Kanfer, J. N. \& Gal, A. E. (1966). Biochem. biophys. Res. Commun. 22, 442.

Kopaczyk, K. C. \& Radin, N. S. (1965). J. Lipid Res. 6, 140.

Long, C., Odavić, R. \& Sargent, E. J. (1967). Biochem. J. $102,216$.

McCaman, R. E. (1962). J. biol. Chem. 237, 672.

McMurray, W. C. \& Rossiter, R. J. (1962). Acta neurol. scand. 38, suppl. 1, p. 32.

Marshall, E. F., Chojnacki, T. \& Ansell, G. B. (1965). Biochem. J. 95, 30 P.

Porcellati, G. (1958). J. Neurochem. 2, 128.

Reiner, J. M. (1953). Arch. Biochem. Biophys. 46, 53.

Richter, D. \& Crossland, J. (1949). Amer. J. Physiol. 159, 247.

Rossiter, R. J. (1964). In Metabolism and Physiological Significance of Lipids, p. 511. Ed. by Dawson, R. M. C. \& Rhodes, D. N. London: John Wiley and Sons (Inc.) Ltd.

Spitzer, H. L., Morrison, K. \& Norman, J. R. (1968). Biochim. biophys. Acta, 152, 552.

Webster, G. R. (1960). Biochim. biophys. Acta, 44, 109.

Wells, M. A. \& Dittmer, J. C. (1967). Biochemistry, 6, 3169.

Zilversmit, D. B., Entenman, C. \& Fishler, M. C. (1943). J. gen. Physiol. 26, 325. 